\section{Effect of Monocyte Migration on Low Density Lipoprotein Transport Across Aortic Endothelial Cell Monolayers}

Mary Territo, Judith A. Berliner, and Alan M. Fogelman Departments of Medicine and Pathology, Center for the Health Sciences, University of California, Los Angeles, California 90024 bstract. Endothelial cell monolayers on polycarbonate filters present a barrier to low density lipoprotein (LDL) and albumin transport. These cells form a relatively tight monolayer as shown by measurements of electrical resistance across the monolayer (15 $\left.\Omega-\mathrm{cm}^{2}\right)$. Monocytes are able to migrate freely across the monolayers in response to chemotactic stimuli. Monocyte chemotaxis across the monolayer caused a marked increase in LDL and albumin transport across the monolayer in the direction of monocyte migration. However, transport in the opposite direction was not significantly increased. These results suggest that monocyte migration across the endothelium could lead to an increased LDL content of the intima.

\section{Introduction}

The accumulation of monocytes and lipoproteins in the intima are important events in the initiation of the atherosclerotic lesion (1). In an attempt to examine the interaction of monocytes and endothelium in the process of lipoprotein transport, we employed a system similar to that initially described by Taylor and colleagues (2) where endothelial monolayers are grown on filters and placed in chemotactic chambers. In such a system, fluid above and below the monolayer can be readily sampled and evaluated for lipoprotein transport. We have examined the extent to which the endothelial monolayer retards low density lipoprotein (LDL) transport and the effect of monocyte migration through the monolayer on this transport process. The rate of transport of albumin has also been examined to determine if $\mathrm{LDL}$ was unique in its transport properties.

Address correspondence to Dr. Territo, University of California at Los Angeles Center for the Health Sciences, Factor Building, Room 11-244, Los Angeles, CA 90024.

Received for publication 16 March 1984 and in revised form 9 August 1984.

\footnotetext{
J. Clin. Invest.

(c) The American Society for Clinical Investigation, Inc. 0021-9738/84/12/2279/06 \$1.00
}

Volume 74, December 1984, 2279-2284

\section{Methods}

Mononuclear cell suspensions. Mononuclear cell suspensions were prepared from heparinized peripheral blood by Ficoll-Hypaque gradient separation (3). In some experiments, pure monocytes were prepared by counterflow centrifugation as previously described (4).

Endothelial cells. Endothelial cells were isolated by collagenase digestion of bovine aorta (5) and plated on culture dishes in Waymouths medium (Gibco \#320-1220; Gibco Laboratories, Grand Island, NY) containing $8 \%$ fetal calf serum. Endothelial cells were passaged with $0.02 \%$ trypsin $0.005 \mathrm{M}$ EDTA and plated at a density of $2 \times 10^{5}$ cells/ $\mathrm{cm}^{2}$ on prepared filters in tissue culture wells and incubated at $37^{\circ} \mathrm{C}$ for 5-7 d, at which time they were observed by phase microscopy for confluency.

Smooth muscle cells. Smooth muscle cells were isolated by the explant method (6) and passaged in medium 199 containing 15\% fetal calf serum. Second and third passages were plated at $10^{5} \mathrm{cells} / \mathrm{cm}^{2}$ on prepared filters in culture wells and incubated for $5 \mathrm{~d}$, at which time they were observed by phase microsopy for confluency.

Polycarbonate filters. Polycarbonate filters, $5 \mu \mathrm{m}$ pore size, $13-\mathrm{mm}$ diameter (Nuclepore \#110413 Pleasanton, CA) were treated for 15 min with $70 \%$ alcohol, rinsed extensively in distilled water, and boiled for $30 \mathrm{~min}$ in $0.1 \%$ gelatin in phosphate-buffered saline. Filters were then placed into tissue culture wells and heated to $60^{\circ} \mathrm{C}$ for $30 \mathrm{~min}$. Glass rings were placed over the filters to hold the edges down. Endothelial or smooth muscle cells were then added onto the filters and cultured.

$L D L$ and albumin preparation. LDL was prepared from the serum of normal fasting subjects by density fractionation in an ultracentrifuge. LDL was obtained in the fraction $d=1.019-1.063 \mathrm{~g} / \mathrm{ml}$ (4). Part of the LDL was labeled with ${ }^{125} \mathrm{I}$ (7) to allow determination of LDL transport. Pentex albumin was utilized and isolated by previous methods (7).

Chemotaxis. Chemotaxis was performed in Boyden chambers (8). Treated $5 \mu \mathrm{m}$ polycarbonate filters, or the endothelial monolayer filter complex were used to separate the upper from the lower wells of the chamber. Unless otherwise stated, a chemotactic factor (20\% serum [AB], or $10^{-9} \mathrm{M} f$-Met-Leu-Phe [Sigma \#F6004, Sigma Chemical Co., St. Louis, MO]) or inactive buffer (Geys medium) was placed in the lower well, and cell suspensions containing $7 \times 10^{5}$ monocytes were placed in the upper well. Chambers were incubated at $37^{\circ} \mathrm{C}$ for 90 min. The filters were stained with Giemsa stain and the number of monocytes migrating to the lower aspect of the filter after this time was determined microscopically using a microgrid, and the results reported as cells per high power field.

LDL and albumin transport. LDL or albumin at a concentration of $100 \mu \mathrm{g} / \mathrm{ml}$ and specific activity of $60,000 \mathrm{cpm} / \mu \mathrm{g}$ ( ${ }^{125} \mathrm{I}$-protein) was added to the upper well of the Boyden chamber, which had initially 
been incubated at $37^{\circ} \mathrm{C}$ for $90 \mathrm{~min}$ unless otherwise stated. At specified times, fluid from the lower well was sampled, centrifuged at $500 \mathrm{~g}$ for $10 \mathrm{~min}$ to remove any cells, and analyzed for trichloracetic acid (TCA) precipitable activity (TCA soluble activity was undetectable in all of our samples). Results are expressed as nanograms of protein transported to the lower well. For some experiments, the ${ }^{125} \mathrm{I}$-LDL or ${ }^{125} \mathrm{I}$-albumin initially was added to the lower well and subsequent samples taken from the upper well.

Electrical resistance. Electrical resistance across the filters with the cell monolayers was measured at $37^{\circ} \mathrm{C}$ in a modified Ussing chamber with two matched Calomel half cells as described by Kim and Crandall (9). Filters lacking cells and filters containing smooth muscle cell layers were employed for comparison studies. Results for type II alveolar epithelial cells using the same apparatus were also used for comparison (10). Resistance $\left(\Omega-\mathrm{cm}^{2}\right)$ was calculated from the ratio $\Delta V / \Delta I$ where $\Delta \mathrm{V}$ is the steady-stage voltage response to a small $\left(10-20 \mu \mathrm{A} \mathrm{cm} \mathrm{cm}^{-2}\right)$ steady current change $(\Delta I)$.

Electron microscopic sections. Electron microscopic sections were prepared after fixing in $2 \%$ buffered gluteraldehyde and processed as described previously (11).

\section{Results}

Evaluation of endothelial monolayers grown on filters. The endothelial cells were seen to grow to confluence on the treated filters by phase microscopy. On electron microscopic evaluation of the monolayers, the endothelial cells were $\sim 5 \mu \mathrm{m}$ in height and the cells displayed what appeared to be close, possibly tight junctional contacts over isolated areas of the cell (Fig. 1). There were many interdigitating cell processes. The cells exhibited a polarity with basement membrane-like material seen beneath the side adjacent to the filter.

The endothelial monolayers exhibited a marked restriction of LDL movement, lowering the transport rate at least 25-fold compared with filters lacking cells (Fig. 2). For comparison, smooth muscle cell monolayers were also evaluated in this system and were shown to have a lesser but still pronounced effect on LDL transport rate. Albumin was transported more rapidly across the endothelial monolayer than was the larger LDL molecule. For these studies of protein transport across the monolayer, a saturating concentration of LDL (100 $\mu \mathrm{g} / \mathrm{ml}$ ) was selected (Fig. 3). The concentration of albumin was also above saturation in these studies (data not shown). Transport across filters without cells was not saturated at this protein concentration, or at concentrations up to $600 \mu \mathrm{g} / \mathrm{ml}$.

The electrical resistance across the endothelial monolayers, although not quite as high as across the epithelial cells, was clearly higher than that across smooth muscle layers or plain filters (Table I).

The relationship of monocyte chemotaxis and protein transport across endothelial monolayers. The endothelial monolayers did not present a barrier to monocyte chemotaxis. Table II presents the data for monocyte migration toward Geys buffer and toward chemotactic factors (human serum [AB] and the chemotactic peptide, $f$-Met-Leu-Phe). Monocyte chemotaxis was essentially the same whether or not endothelial cells were present on the filter. There was no difference whether mixed

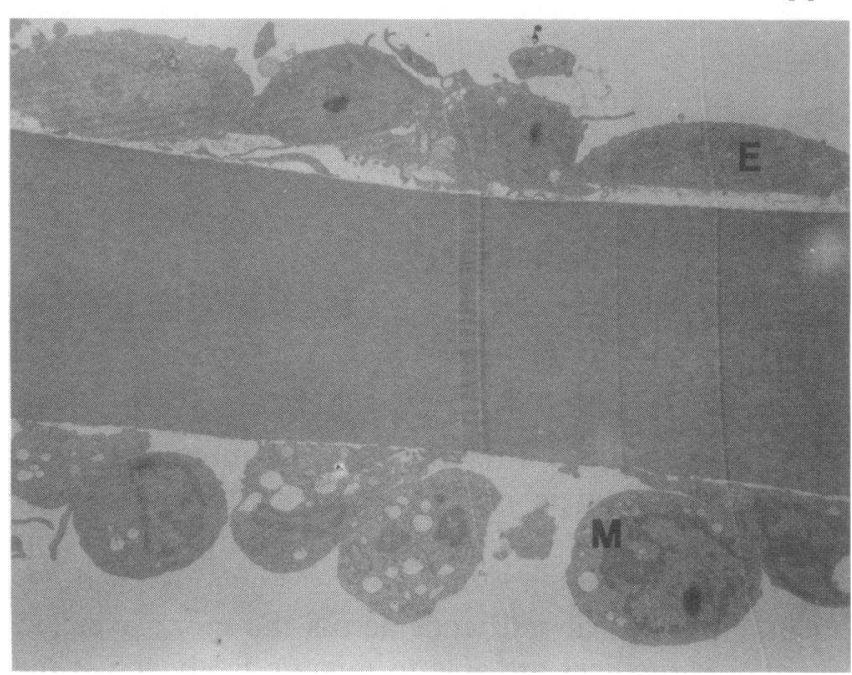

B

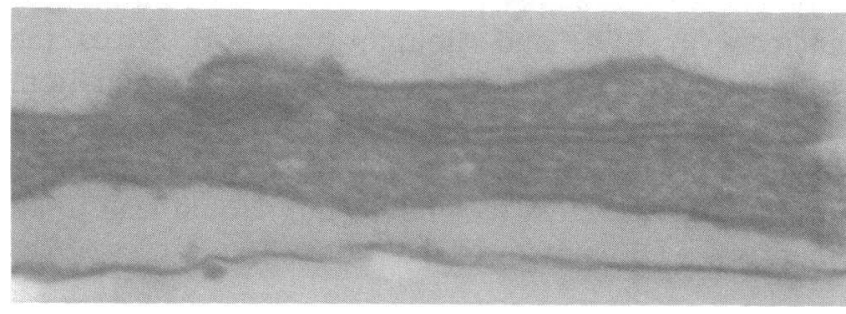

Figure 1. (A) Structure of the endothelial monolayer on a polycarbonate filter. Endothelial cell structure in a region of polycarbonate filter lacking pores. Monocytes had been added to the upper well of the Boyden chamber and chemotactic factor in the lower well. Monocytes (M) seen on the underside of the filter have crossed the filter through distant pores (not visible in this section) and have migrated along the underside of the filter to this area. Regions of junctional contact between endothelial cells $(E)$ are quite extensive. $(\times 5,000)$. (B) A higher magnification $(\times 25,000)$ of the junctional areas between adjacent endothelial cells.

mononuclear cells or pure monocytes were added to the system. Electron microscopic evaluation of the endothelialfilter complex in the presence of monocyte chemotaxis is shown in Fig. 4. In areas where a monocyte has recently passed through the monolayer, the endothelial cell processes are connected by altered and attenuated junctional areas (Fig. 4). Monocytes were never seen going through endothelial cells, only between them.

A consequence of monocyte chemotaxis through the monolayer was that the rate of transport of LDL through the monolayer increased dramatically in the direction of the monocyte migration (Fig. 5). LDL was readily diffusable across the plain filter with $4,500 \pm 434 \mathrm{ng}$ of LDL being transported at $1 \mathrm{~h}$ either from the upper to the lower or from the lower to the upper well of the Boyden chambers. When endothelial 


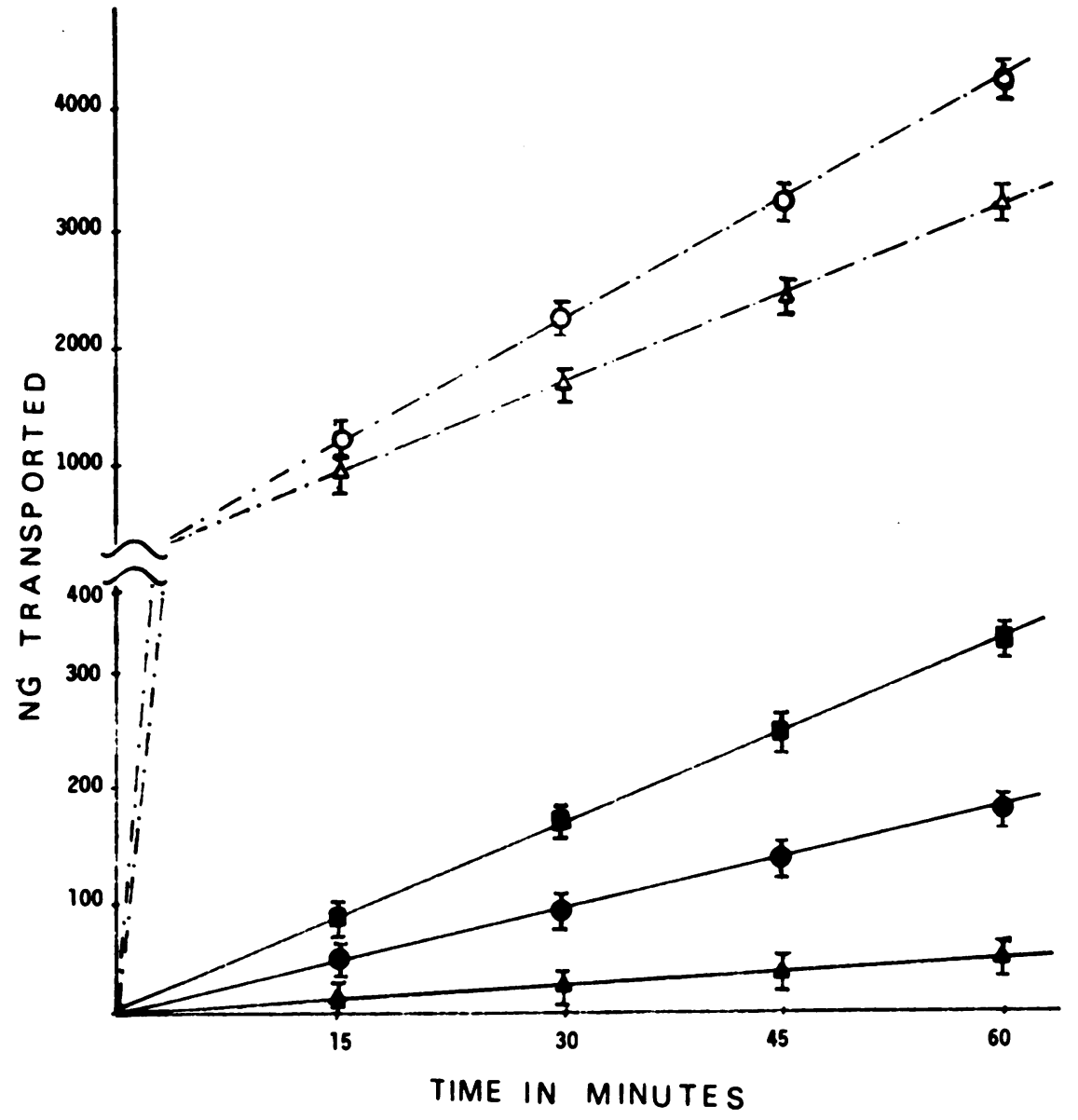

Figure 2. Nanograms (NG) of LDL or albumin moving across plain filters $(F)$ or the cellfilter complex. ---O-.-, albumin transport across $F ;-\cdot-\Delta-\cdot-$, LDL transport across $F$; $-\bullet-$, albumin transport across endothelial monolayer-filter complex; $-\Delta-$, LDL transport across endothelial monolayer-filter complex; - - , LDL transport across smooth muscle cell monolayer-filter complex. Note that the vertical axis changes above the $400 \mathrm{ng}$ mark. Values shown are mean \pm SD.

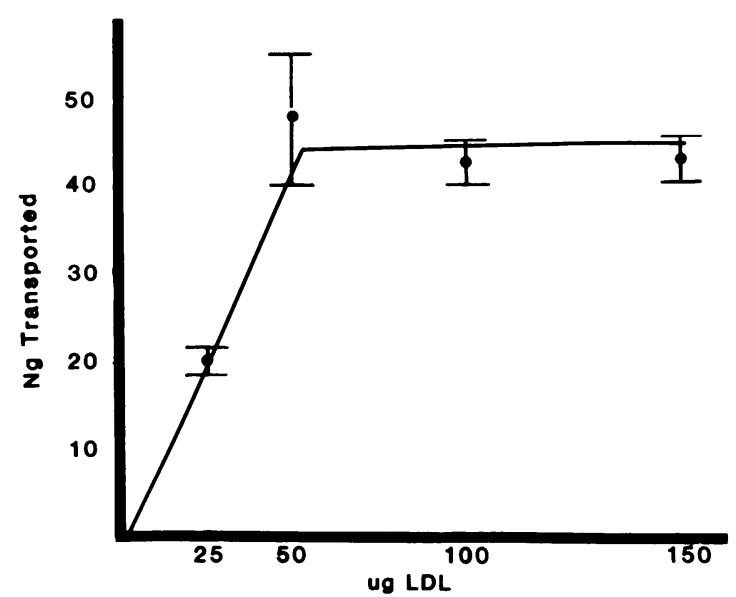

Figure 3. Effect of concentration on LDL transport. ${ }^{125} \mathrm{I}-\mathrm{LDL}$ at a specific activity of $10,000 \mathrm{cpm} / \mu \mathrm{g}$ was placed in the upper well of a Boyden chamber in which filters with endothelial cells had been placed. After $1 \mathrm{~h}$, the nanograms of lipoprotein transported to the lower well were determined. Values represent mean \pm SD of four values. monolayers were present on the filter, the LDL transport was markedly reduced with $<30 \pm 11$ (range, $21-49$ ) $\mathrm{ng}$ of LDL reaching the opposite well at $1 \mathrm{~h}$. The presence of chemotactic factor in the lower well (without monocytes in the system) or monocytes in the upper well (with no chemotactic factor in the lower well) did not increase the rate of transport of LDL across the endothelial monolayers. With migration of monocytes across the endothelium from the upper to the lower well in response to a chemotactic stimulus, there was a sixfold increase in LDL transported from the upper to the lower well after 1 h $(175 \pm 30 \mathrm{ng}$ LDL at $1 \mathrm{~h}$, range 125-230, Fig. $5 A)$. This increase in LDL transport was only seen in the direction of monocyte movement. When ${ }^{125} \mathrm{I}-\mathrm{LDL}$ was placed in the lower well and monocytes were induced to migrate from the upper to the lower well (Fig. $5 \mathrm{~B}$ ), there was no increase in the transport rate of ${ }^{125} \mathrm{I}-\mathrm{LDL}$ from the lower to the upper well. Since our samples of ${ }^{125} \mathrm{I}-\mathrm{LDL}$ measurements were centrifuged to remove any cells before measuring activity and since all of the radioactivity was TCA precipitable, the data represent LDL movement rather than disassociated label or cell-associated LDL transport. Albumin also showed an increased transport 
Table I. Electrical Resistance across Filters containing Cell Monolayers

\begin{tabular}{lc}
\hline Cells on filters & Resistance $\left(\Omega-\mathrm{cm}^{2}\right)$ \\
\hline None & $0.5 \pm 0.6(4)$ \\
Smooth muscle & $0.8 \pm 1.0(4)$ \\
Endothelial & $15 \pm 5 \quad(6)$ \\
Epithelial & $>300^{*}$ \\
\hline
\end{tabular}

Values represent mean $\pm \mathrm{SD}(n)$

* As reported in reference 10 .

rate during monocyte chemotaxis across the monolayer (Fig. 6), being increased approximately fourfold in the direction of monocyte migration after $1 \mathrm{~h}$. Movement in the opposite direction was also accelerated, though only 1.8 -fold. In all of these studies, the LDL or albumin was added after an initial preincubation of the chambers $( \pm$ monocytes and chemotactic factor) at $37^{\circ} \mathrm{C}$ for $90 \mathrm{~min}$. This was found to be the optimum preincubation period. At 30 min preincubation, protein transport was minimal. It was submaximal at $60 \mathrm{~min}$, maximal at $90 \mathrm{~min}$ of incubation, and no further increase was seen at $120 \mathrm{~min}$.

We interpret these data as indicating that monocytes disrupt cell junctions during diapedesis, allowing LDL to move from the upper to the lower well, but not in the reverse direction. This tendency of a unidirectional transport was also seen with albumin.

\section{Discussion}

The data suggest a unidirectional transport of LDL across endothelial cells as a result of monocyte chemotaxis. The endothelial monolayers used in this system have properties characteristic of vascular endothelium. The monolayers demonstrated polarity of the cells and the presence of tight junctions and cell process interdigitations, both characteristic of the endothelium in vivo (12). The extent of electrical resistance across the aortic endothelium in vivo is not known and thus

Table II. Monocyte Chemotactic Response Across Plain Filters or Endothelial Monolayer Filter Complex in Response to Normal Serum (AB) or Chemotactic Peptide f-Met-Leu-Phe (F-MLP)

\begin{tabular}{llc}
\hline Endothelium & Chemotactic factor & Monocyte migration \\
\hline & & cells/high power field \\
Absent & None & $3 \pm 1(10)$ \\
Absent & AB & $98 \pm 4(10)$ \\
Absent & F-MLP & $53 \pm 4(10)$ \\
Present & None & $5 \pm 1(10)$ \\
Present & AB & $92 \pm 3(10)$ \\
Present & F-MLP & $53 \pm 2(10)$
\end{tabular}

Values represent mean $\pm \mathrm{SD}(n)$.

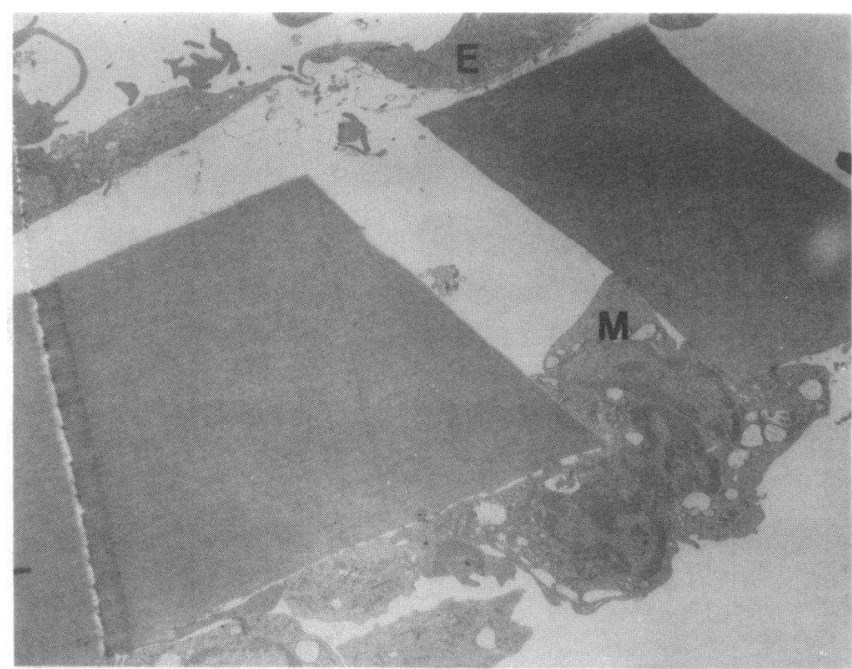

Figure 4. Endothelial junction at the point of monocyte diapedesis. The monocyte $(M)$ (originally in the upper well of the Boyden chamber) has recently migrated into a pore in response to the chemotactic factor. Note the attenuated endothelial junctions over the pore. Basement membrane-like material can be seen on the underside of the endothelium $(E)$ (several of the endothelial cells have artificially lifted up from the filter surface during preparation for electron microscopy $(\times 5,000)$.

direct comparison with our data is not possible. However, it is significant that resistance across the endothelial monolayer is 10-fold higher than a confluent smooth muscle layer suggesting close cell contact. Resistance in the range we observed can be caused by a combination of incomplete tight junctions and/or extensive interdigitations (E. Wright, personal communication). At this time, it is not possible to determine in vivo or in vitro which of these is more important.

The rate of albumin and possibly LDL transport across the in vitro monolayers is similar to that seen in vivo, providing the best evidence for the similarity of the in vivo and in vitro systems.

The amount of albumin transported through the monolayer per centimeter squared per hour is $150 \mathrm{ng}$, a value less than the mean but within the range of that reported for transport across swine aorta in vivo (13) and which is similar to that found in a carotid perfusion system (14). The values for LDL transport are similar to that found in vivo (15), if the rate of radioactive and nonradioactive LDL transport are assumed to be the same, an assumption that is not testable at the present time. While the evidence would suggest that transport rates through the monolayers utilized in this study are similar to that in vivo, an assumption of identity with in vivo monolayers would clearly be unwarranted at this time.

Monocytes are known normally to migrate from the blood into the vessel wall. Electron microscopic studies by Marchesi (16) and Florey and Grant (17) have demonstrated that monocytes initially marginate and adhere to endothelial surfaces, insert pseudopodia between endothelial cells, migrate 


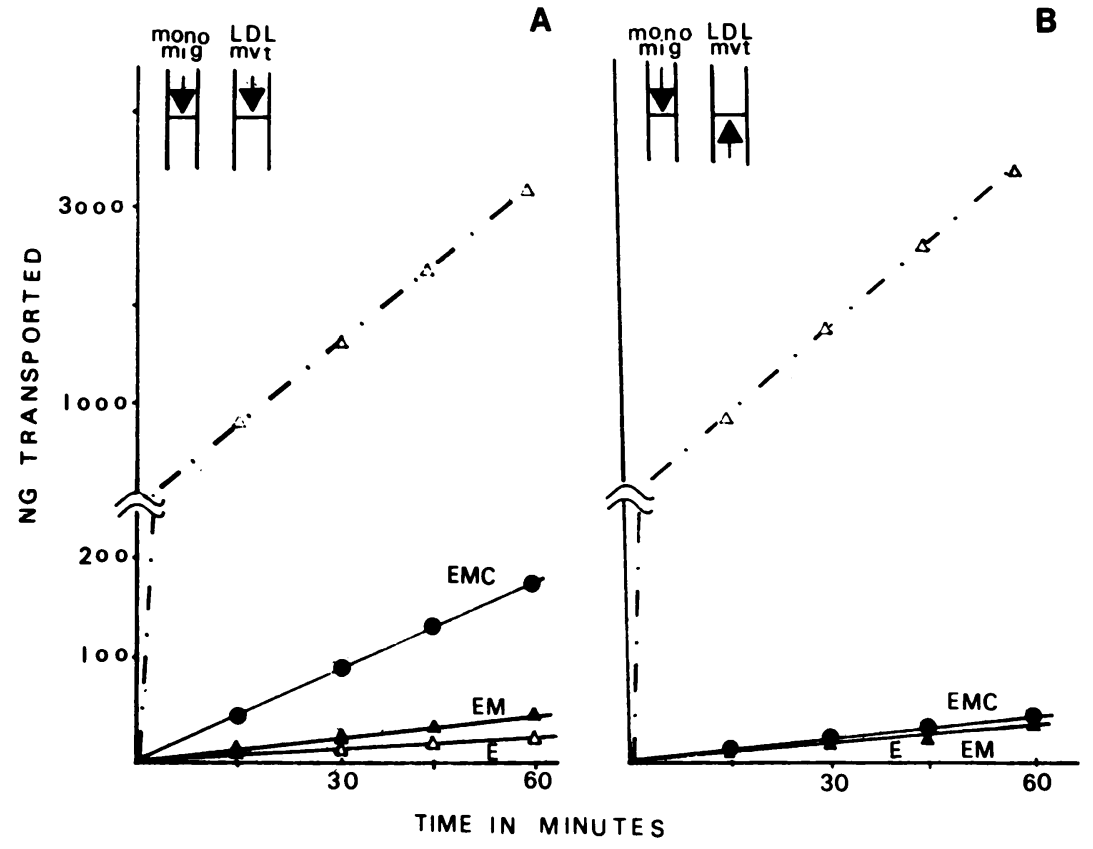

Figure 5. Movement of ${ }^{125} \mathrm{I}-\mathrm{LDL}$ in Boyden chambers. $(A)$ Human LDL at a concentration of $100 \mu \mathrm{g} / \mathrm{ml}$ and specific activity of $60,000 \mathrm{cpm} / \mu \mathrm{g}$ ( $\left.{ }^{125} \mathrm{I}-\mathrm{LDL}\right)$ was added to the upper well. At various times, fluid from the lower well was sampled for determination of radioactivity. Values represent nanograms (NG) of LDL transported to the lower well. - $-\Delta-\cdot-$, Filters alone ( \pm chemotactic factor in the lower well); - - , EMC (endothelial monolayers on the filter, monocytes in the upper well, chemotactic factor in the lower well); $-\triangle-$, EM (endothelial monolayers on the filter, monocytes in the upper well, buffer in the lower well); $-\Delta-, E$ (endothelial monolayers on the filter \pm chemotactic factor in the lower well, no monocytes). Note that the vertical scale changes above the $200 \mathrm{ng}$ mark. Values represent mean $\pm \mathrm{SD}$. The arrows show the direction of monocyte migration (mig) and LDL movement (mvt). (B) Identical to $A$ except that the ${ }^{125}$ I-LDL was added to the lower well and the fluid was sampled at various times from the upper well. E and EM were superimposable.

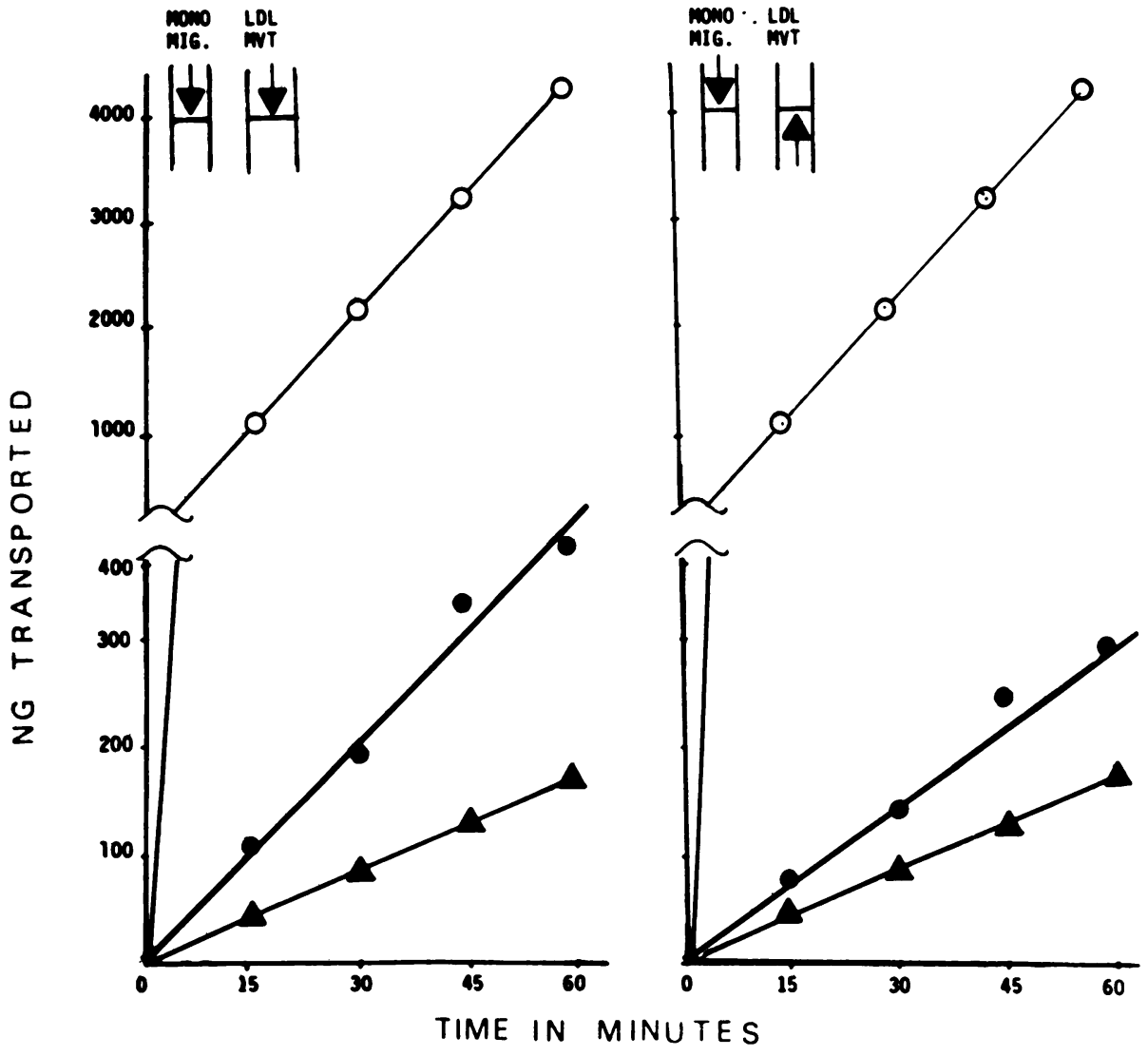

Figure 6. Movement of ${ }^{125} \mathrm{I}$-albumin in Boyden chambers at a concentration of $100 \mu \mathrm{g} / \mathrm{ml}$ and specific activity of $60,000 \mathrm{cpm} / \mu \mathrm{g}$. $(A){ }^{125}$ Albumin was added to the upper well. At various times, fluid from the lower well was sampled for determination of radioactivity. Values represent nanograms of albumin transported to the lower well. $-0-$, Filters alone ( \pm chemotactic factor in the lower well); $-\Delta-$, endothelial monolayers on the filter ( \pm monocytes in the upper well, buffer in the lower well); - $\bullet-$, endothelial monolayers on the filter plus chemotactic factor in the lower well, monocytes in the upper well. Note that the vertical scale changes above the $400 \mathrm{ng}$ mark. Values represent mean $\pm \mathrm{SD}$. $(B)$ Identical to panel $A$ except that the albumin was added to the lower well and the fluid was sampled at various times from the upper well. 
into the subendothelium where they remain for a brief period, and then pass freely through venules and arterioles into the surrounding connective tissue. The migration out of the vessel is greatly accentuated under the influence of chemotactic factors. The diapedesis of monocytes through the wall of large vessels also appears to be a normal event (18) that is accentuated after cholesterol feeding (19). In our in vitro system, monocytes passed freely across the endothelial monolayers in response to chemotactic stimuli. Electron microscopic studies (Fig. 4) indicated that the monocytes migrated between adjacent endothelial cells. Subsequent to the migration, there appeared to be an attenuation of the junctional connections of the endothelial cells.

Smith and Staples (20) have demonstrated an increased concentration of LDL in the intima of human aorta in comparison with that in the circulating plasma. While there are a number of possibilities to explain this finding, our data would suggest that part of the explanation may relate to a one-way passage of LDL into the intima as a result of the passage of monocytes through the endothelium. Our data have shown that monocyte movement across the endothelium can accelerate the normally low transport of lipoproteins and albumin into the intima. Others have shown that neutrophils accelerate the movement of albumin across an endothelial monolayer (21). At this time, we have not defined a specific mechanism for the essentially one-way passage of LDL. Since our findings excluded cell-associated LDL, we think it unlikely that the LDL simply binds to the monocyte and transverses the endothelium with it, although a very transient association and subsequent disassociation after the monocyte has crossed cannot yet be ruled out. Some interaction with the basement membrane or adjacent endothelial surface may be operative in inhibiting the backward flow of LDL. It is also likely that a microcurrent flow is established as the monocyte crosses the endothelium, which would augment the passage of LDL in the same direction as monocyte movement. The fact that albumin also had a tendency for unidirectional transport shows that this movement pattern is not specific for LDL, but appears more pronounced with LDL than albumin. It will be important in future studies to determine whether other lipoproteins move similarly to LDL.

Various endothelial cell culture systems $(21,22)$ have provided useful information about endothelial cell function. Since the interaction of lipoproteins, monocytes, and endothelial cells appears to be important in the initiation of atherosclerosis, the in vitro system used in this study may be a useful model for the investigation of these interactions.

\section{Acknowledgments}

The authors would like to thank Jim Yu, Laura Almada, and Alice Carter for their excellent technical assistance; and Dr. Edward Crandall and Dr. Barbara Goodman for their assistance with the electrical resistance measurements.

This research was supported by a grant from the American Heart Association, Greater Los Angeles Affiliate, U. S. Public Health Service grant HL 30568, and the Laubisch Fund.

\section{References}

1. Ross, R. 1981. Atherosclerosis: a problem of the biology of arterial wall cells and their interactions with blood components. Arteriosclerosis. 1:293-311.

2. Taylor, R. F., T. H. Price, S. M. Schwartz, and D. C. Dale. 1981. Neutrophil-endothelial cell interactions on endothelial monolayers grown on micropore filters. J. Clin. Invest. 67:584-587.

3. Boyum, A. 1968. Isolation of mononuclear cells and granulocytes from human blood. Scandin. J. Clin. Lab. Invest. 21:77-89.

4. Fogelman, A. M., M. E. Haberland, J. Seager, M. Hokum, and P. A. Edwards. 1981. Factors regulating the activities of the low density lipoprotein receptor and the scavenger receptor on human monocytemacrophages. J. Lipid Res. 22:1131-1141.

5. Schwartz, S. M. 1978. Selection and characteristics of bovine aortic endothelial cells. In Vitro (Rockville). 14:966-980.

6. Chamley-Campbell, J., G. R. Campbell, and R. Ross. 1979. The smooth muscle cell in culture. Physiol. Rev. 59:1-61.

7. Fogelman, A. M., I. Schechter, J. Seager, M. Hokom, J. S. Child, and P. A. Edwards. 1980. Malondialdehyde alteration of LDL leads to cholesterol ester accumulation in human monocyte-macrophages. Proc. Natl. Acad. Sci. USA. 74:2214-2218.

8. Keller, H. U., J. W. Hess, and H. Cottier. 1974. The in vitro assessment of leukocyte chemotaxis. Antibiot. Chemother. (Basel). 19:112-125.

9. Kim, K. J., and E. D. Crandall. 1982. Effects of exposure to acid on alveolar epithelial water and solute transport. J. Appl. Physiol. 52:902-909.

10. Goodman, B. E., and E. D. Crandall. 1984. Permeability of cultured monolayers of type II alveolar epithelial cells to inulin. Fed. Proc. 43:829.

11. Berliner, J. A. 1979. Formation of enlarged mitochondria in a liver cell line in response to a synthetic glucocorticoid. J. Cell Biol. 64:711-716.

12. Huttner, I., M. Boutet, and R. H. More. 1973. Studies on protein passage through endothelium. Lab. Invest. 28:672-677.

13. Bell, F. P., A. S. Gallus, and C. J. Schwartz. 1974. Focal and regional patterns of uptake and transmural distribution in the young pig. Exp. Mol. Pathol. 20:281-292.

14. Chobanian, A. V., J. O. Menzonian, J. Shipman, K. Health, and C. C. Haudenschild. 1983. Circ. Res. 53:805-814.

15. Bratzler, R. L., G. M. Chisolm, C. K. Colton, K. A. Smith, and R. S. Lees. 1977. The distribution of labelled low density lipoproteins across the rabbit aorta in vivo. Atherosclerosis. 28:289-307.

16. Marchesi, V. T. 1961. The site of leukocyte emigration during inflammation. Q. J. Exp. Physiol. Cogn. Med. Sci. 46:115-118.

17. Florey, H. W., and L. H. Grant. 1961. Leukocyte migration from small blood vessels stimulated with ultraviolet light: an electron microscopic study. J. Pathol. \& Bacteriol. 82:13-18.

18. Joris, I., E. Stetz, and G. Majno. 1979. Lymphocytes and monocytes in the aortic intima. Atherosclerosis. 34:221-231.

19. Gerrity, G. G. 1981. The role of the monocyte in atherogenesis. 1. Transition of blood borne monocytes into foam cells in fatty lesions. Am. J. Pathol. 103:181-190.

20. Smith, E. B., and E. M. Staples. 1980. Distribution of plasma proteins across the human aortic wall. Atherosclerosis. 37:579-590.

21. Davies, P. T., and C. Kerr. 1982. Co-cultivation of vascular endothelial and smooth muscle cell using microcarrier techniques. Exp. Cell Res. 141:455-459.

22. Bussolari, S. R., C. F. Dewey, and M. A. Gimbrone. 1900. Apparatus for subjecting living cells to fluid shear stress. Rev. Sci. Instrum. 53:1851-1858. 